\title{
Article \\ Herb Sanqi-Derived Compound K Alleviates Oxidative Stress in Cultured Human Melanocytes and Improves Oxidative-Stress-Related Leukoderma in Guinea Pigs
}

\author{
Suwei Tang ${ }^{1,2}$, Lingli Yang ${ }^{1, *(\mathbb{D}}$, Yasutaka Kuroda ${ }^{1,3} \mathbb{D}$, Sylvia Lai ${ }^{1}$, Shaoqiong Xie ${ }^{2}$, Huimin Zhang ${ }^{4,+}$ \\ and Ichiro Katayama ${ }^{1}$
}

check for updates

Citation: Tang, S.; Yang, L.; Kuroda, Y.; Lai, S.; Xie, S.; Zhang, H.;

Katayama, I. Herb Sanqi-Derived Compound K Alleviates Oxidative Stress in Cultured Human Melanocytes and Improves Oxidative-Stress-Related Leukoderma in Guinea Pigs. Cells 2021, 10, 2057. https://doi.org/ 10.3390/cells10082057

Academic Editor: Alexander E. Kalyuzhny

Received: 21 June 2021

Accepted: 5 August 2021

Published: 11 August 2021

Publisher's Note: MDPI stays neutral with regard to jurisdictional claims in published maps and institutional affiliations.

Copyright: (c) 2021 by the authors. Licensee MDPI, Basel, Switzerland. This article is an open access article distributed under the terms and conditions of the Creative Commons Attribution (CC BY) license (https:// creativecommons.org/licenses/by/ $4.0 /)$.
1 Department of Pigmentation Research and Therapeutics, Graduate School of Medicine, Osaka City University, Osaka 5450051, Japan; kellyshadow_tsw@hotmail.com (S.T.); kuroda.yasutaka@kao.com (Y.K.); s-lai@l.wdb-eu.com (S.L.); espaikoffice@gmail.com (I.K.)

2 Department of Dermatology, Shanghai Skin Disease Hospital, Tongii University School of Medicine, Shanghai 200443, China; 18017336630@189.cn

3 Biological Science Laboratories, Kao Corporation, Kanagawa 2500002, Japan

4 Department of Dermatology, Shuguang Hospital Affiliated to Shanghai University of Traditional Chinese Medicine, Shanghai 200021, China; zhanghm@shutcm.edu.cn

* Correspondence: yang.lingli@med.osaka-cu.ac.jp; Tel./Fax: +81-665-567-618

+ This author is the co-corresponding author.

\begin{abstract}
Sanqi, a traditional Chinese herb, is widely used for cardiovascular diseases, and its neuroprotective effects against oxidative stress were recently discovered. The purpose of this study was to investigate whether Sanqi-derived compound K (Sanqi-CK), an active metabolite of Sanqi, could protect melanocytes from oxidative stress. Cultured human primary skin epidermal melanocytes (HEMn-MPs) were treated with hydrogen peroxide $\left(\mathrm{H}_{2} \mathrm{O}_{2}\right)$ in the presence or absence of Sanqi-CK. Sanqi-CK exhibited protective effects against $\mathrm{H}_{2} \mathrm{O}_{2}$-induced cell death by reducing oxidative stress. In addition, treatment with Sanqi-CK reversed the decreased glutathione reductase activity and decreased ratio of reduced glutathione (GSH) / oxidized glutathione (GSSG) seen in $\mathrm{H}_{2} \mathrm{O}_{2}$-treated melanocytes. Furthermore, topical application of Sanqi-CK alleviated leukoderma in guinea pigs, a disorder characterized by melanocyte cell death resulting from rhododendrol-induced oxidative stress. Taken together, these data suggest that Sanqi-CK protects melanocytes against oxidative stress, and its protective effects are associated with modulating the redox balance between GSH and GSSG and activating glutathione reductase. Thus, Sanqi-CK may be a good candidate for preventing melanocyte loss in oxidative-stress-associated pigmentary disorders.
\end{abstract}

Keywords: Sanqi; melanocytes; oxidative stress; leukoderma

\section{Introduction}

Oxidative stress is characterized by an imbalance between free radical formation and the body's antioxidant capacity. Oxidative stress is widely believed to cause serious cellular damage and lead to various pathophysiologic conditions. Skin is the largest barrier organ of our body. It plays an important role in protecting against ultraviolet (UV) irradiation, air pollution, chemicals, pathogens, and other harmful factors that induce oxidative stress. Skin epidermal melanocytes are derived from the spinal portion of the neural crest [1] and are especially vulnerable to oxidative stress, owing to the pro-oxidant state generated during melanin synthesis [2].

Loss of functional melanocytes is the pathologic hallmark of depigmented macules in patients with vitiligo. Vitiligo is the most commonly acquired skin pigmentary disorder, affecting $0.5-1 \%$ of the world's population. It is characterized by white patches of skin resulting from loss of functional epidermal melanocytes [3,4]. The cause of this loss is not fully understood, but both intrinsic (genetic, immunologic, neural, and biochemical) and 
extrinsic (environmental) factors contribute to vitiligo [4,5]. An increasing body of evidence has suggested that oxidative stress is a major culprit in melanocyte loss; it is considered a key factor in both the onset and progression of vitiligo [6-9]. High levels of oxidative stress and low levels of enzymatic and nonenzymatic antioxidants have been found in the skin and blood of patients with vitiligo [6-10]. An imbalance between oxidants and antioxidants is suggested as the initial pathogenic event in melanocyte degeneration, playing a crucial role in vitiligo pathogenesis [7].

Accordingly, oxidative stress has been discussed as a promising target for vitiligo treatment. Approaches and treatments using antioxidants to suppress or reverse oxidative stress in the epidermis and even achieve re-pigmentation are being studied. The majority of known exogenous antioxidants are phytochemicals derived from plants. Regulating oxidative stress through administration of naturally occurring substances with antioxidant properties is therefore a potentially promising treatment strategy for vitiligo.

Sanqi is a traditional Chinese medicine derived from the roots of Panax notoginseng. It has a long history of medical use spanning over four centuries, and has been referred to as "more precious than gold" [11]. It has been widely used to treat coronary artery disease [12]. Recently, compounds in Sanqi were reported to help reduce beta-amyloid toxicity, slow memory decline, and improve memory and spatial learning in a mouse model of Alzheimer's disease [13]. In another recent study, Sanqi was shown to have prominent anti-anxiety, antidepressant, and anti-insomnia effects [14]. Sanqi is also considered a promising product for fighting the effects of aging and neurodegenerative diseases [15]. Although vitiligo has features in common with neurodegenerative diseases $[1,16]$, and melanocytes are derived from neural crest cells, no study has heretofore examined the effects of Sanqi in vitiligo.

Sanqi has a distinct ginsenoside profile when compared with other ginseng herbs, including Korean, Siberian, and American ginseng. There are numerous studies about Korean ginseng, whereas reports about Chinese Sanqi are relatively few. The most effective compounds found in Sanqi are four unique saponins, including ginsenoside $\operatorname{Rg} 1$, ginsenoside $\mathrm{Rb} 1$, ginsenoside Re, and notoginsenoside R1 [11]. As a saponin-rich plant, Sanqi could be a good therapeutic candidate with antioxidant properties. Like many other herbal medicines, Sanqi is usually taken orally. After digestion, its constituents are exposed to gut microflora in the gastrointestinal tract and biotransformed into active metabolites. Compound K (Sanq-CK) is a major bioactive metabolite absorbed into the systemic circulation [17], and possesses much stronger biological activity.

Recent reports indicate that Sanqi-CK has good activity in various oxidative-stressrelated conditions. For instance, Sanqi-CK has been shown to alleviate hypolipidemiaassociated oxidative stress in high-fat-fed rats through enhancing the activity of hepatic antioxidants via increasing superoxide dismutase levels and glutathione peroxidase activities [18]. Furthermore, Sanqi-CK has demonstrated protective effects against nephropathy in high-fat-fed/streptozotocin-induced mice, acting by significantly reducing oxidative stress and reducing reactive oxygen species (ROS)-mediated activation of inflammasome assembly [19]. Sanqi-CK has also been shown to enhance memory function and reduce neuronal apoptosis by activating the antioxidant system [20]. However, it is unknown whether Sanqi-CK can protect melanocytes from oxidative stress.

Therefore, the current study was conducted to evaluate whether Sanqi-CK protects human melanocytes from oxidative stress and to clarify the underlying molecular mechanisms. We used hydrogen peroxide $\left(\mathrm{H}_{2} \mathrm{O}_{2}\right)$ to stimulate oxidative stress in normal human primary epidermal melanocytes as an in vitro model and topical rhododendrol to induce oxidative stress in melanocytes of the dorsal skin in guinea pigs as an in vivo model.

\section{Materials and Methods}

\subsection{Materials}

Powdered CK (Figure 1b, purity: $>98.0 \%$ ) from Sanqi-extract (i.e., Sanqi-CK) was provided by Sichuan Weikeqi Biological Technology Co., Ltd. (Sichuan, China). It was 
dissolved in dimethyl sulfoxide (DMSO) for in vitro experiments and constituted into an ointment $(2 \%)$ for in vivo experiments. For in vitro experiments, the final culture concentration of DMSO in all the treatments was $0.1 \% v / v$ in growth medium.

(a)
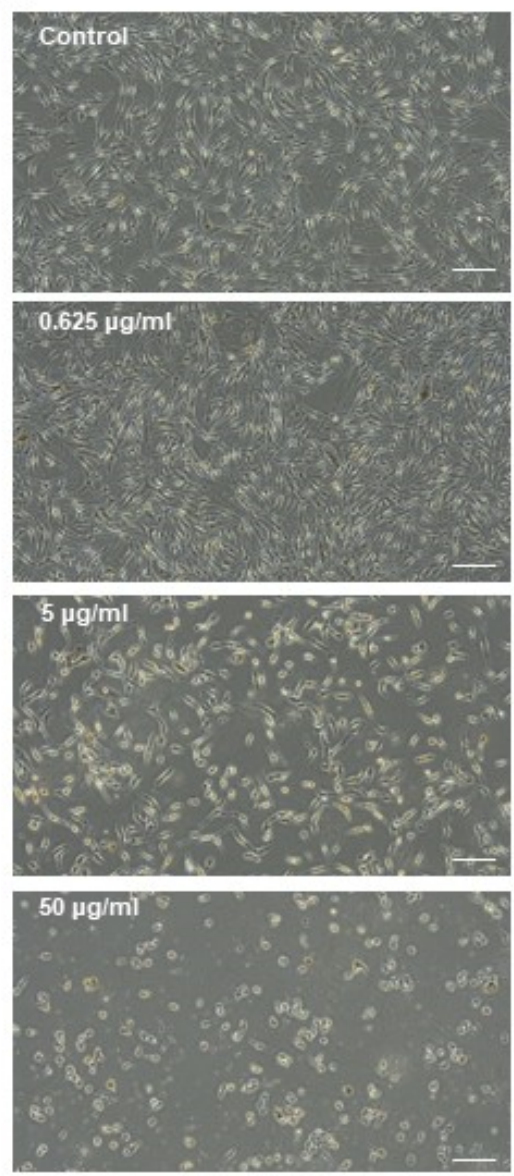

(b)

The molecular structure of Sanqi-CK

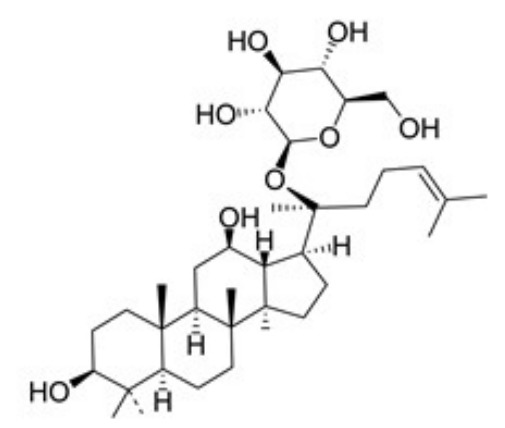

Cultured human melanocytes
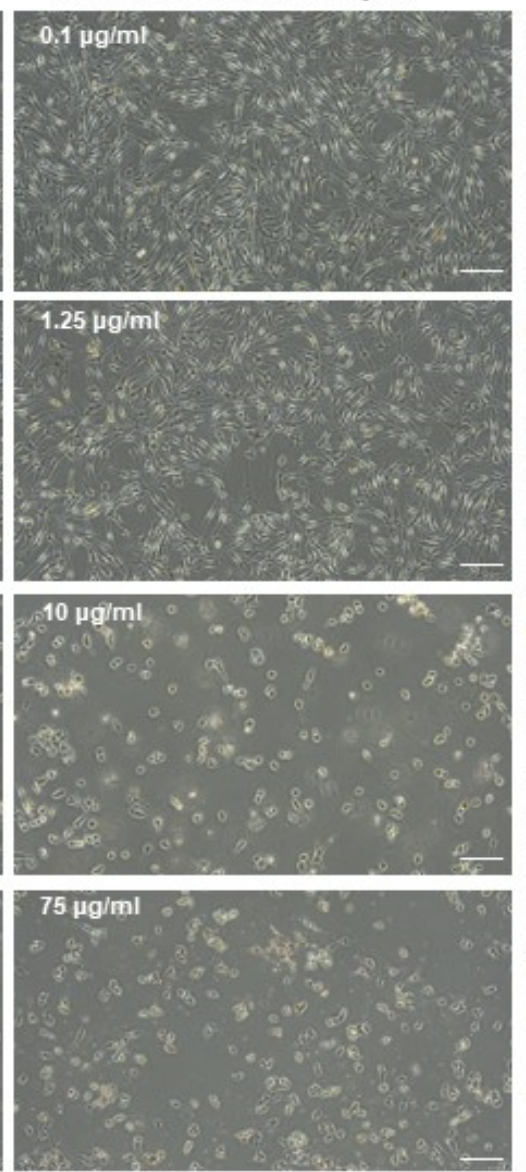

(c)

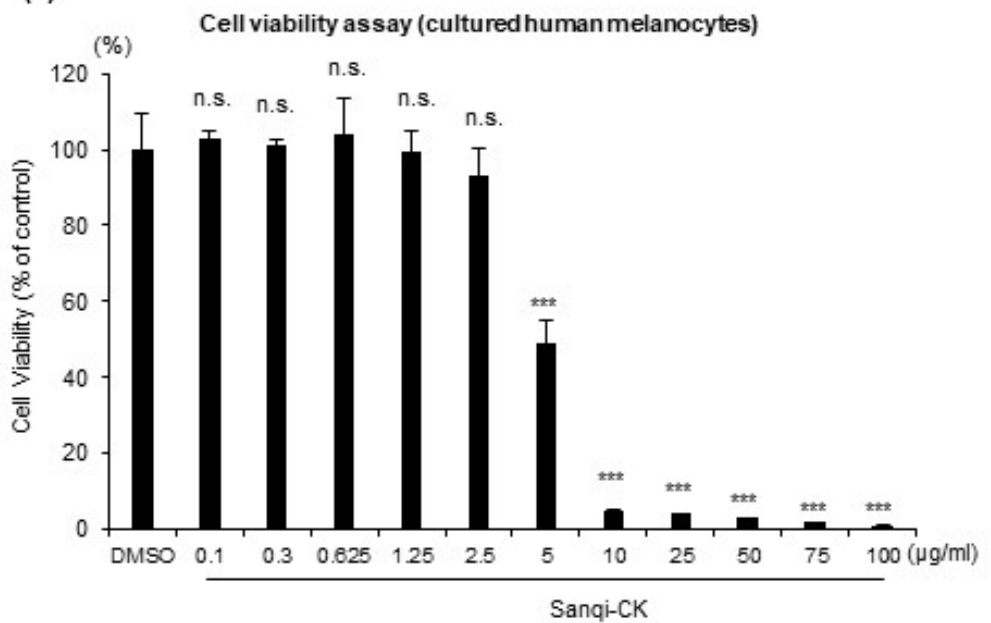

Figure 1. Cytotoxicity analyses by morphologic examination and MTT assay. Cultured human primary epidermal melanocytes (HEMn-MPs) were treated with increasing concentrations of Sanqi-CK $(0.1-100 \mu \mathrm{g} / \mathrm{mL})$ for $24 \mathrm{~h}$. (a) Changes in melanocyte morphology were observed via bright-field microscopy; white bar, $50 \mu \mathrm{m}$. (b) Molecular structure of Sanqi-CK. (c) Cell viability was assessed by MTT assay. Data in (c) represent the results of three independent experiments and are shown as mean \pm SD. n.s., no significant difference; ${ }^{* * *} p<0.01$; compared with control (DMSO) according to one-way analysis of variance (ANOVA) followed by Dunnett's test. 
Rhododendrol (4-(4-hydroxyphenyl)-2-butanol, Rhododenol ${ }^{\circledR}$ ) was kindly provided by Kanebo Cosmetics Inc. (Tokyo, Japan). A stock solution of 20\% (w/v) rhododendrol was prepared in a $50 \%$ ethanol $/ 50 \%$ sesame oil $(v / v)$ mixture.

\subsection{Cell Culture}

Normal human primary skin epidermal melanocytes from moderately pigmented neonatal foreskin (HEMn-MPs) were purchased from Invitrogen (Thermo Fisher Scientific, Carlsbad, CA, USA) and cultured in Medium 254 (M-254-500; Thermo Fisher Scientific) supplemented with $1 \%(v / v)$ human melanocyte growth supplement (Thermo Fisher Scientific) at $37^{\circ} \mathrm{C}$ in an atmosphere containing $5 \%(v / v) \mathrm{CO}_{2}$. The melanocytes were used at passages 8 to 11 . Cells were seeded into 6-well plates at a density of $5 \times 10^{5}$ cells $/$ well for $12 \mathrm{~h}$ before treatment. They were then treated with $\mathrm{H}_{2} \mathrm{O}_{2}$ (Wako, Osaka, Japan) and Sanqi-CK at indicated concentrations and for specific time periods prior to RNA and protein extraction.

\subsection{MTT Assay}

HEMn-MPs $\left(1 \times 10^{4}\right.$ cells / well $)$ were cultured in 96-well flat-bottom tissue culture plates. After completion of the experimental treatments, the cells were washed three times with cold phosphate-buffered solution (PBS), and cell viability was evaluated using the Cell Count Reagent SF colorimetric assay (Nacalai Tesque, Kyoto, Japan). Briefly, $10 \mu \mathrm{L}$ of Cell Count Reagent SF was added to each well, and the cells were incubated for $2 \mathrm{~h}$ at $37^{\circ} \mathrm{C}$. Cell viability was determined colorimetrically by measuring $\mathrm{OD}_{450}$ with a microplate reader (Model 550; Bio-Rad Laboratories, Hercules, CA, USA). The percentage of viable cells was calculated as follows: percentage viable cells $=\mathrm{T} / \mathrm{C} \times 100$, in which $\mathrm{T}$ and $\mathrm{C}$ were the mean $\mathrm{OD}_{450}$ of the treated and control groups, respectively.

\subsection{Melanin Content Assay}

To determine melanin content, cells were first dissolved in $200 \mu \mathrm{L}$ of $1 \mathrm{~N} \mathrm{NaOH}$ for $30 \mathrm{~min}$ at $100{ }^{\circ} \mathrm{C}$ to solubilize the melanin. Melanin content of the cell suspensions was then quantified by recording the absorbance at $405 \mathrm{~nm}$, as described previously [21]. Melanin content was calculated and corrected based on the cell number.

\subsection{Cell Counting Assay}

Viable cell number was manually counted by trypan blue exclusion (Trypan Blue Dye, 0.40\% solution, \#1450013, Bio-Rad Laboratories, Hercules, CA, USA) using a disposable cell counting chamber (C-Chip, Neubauer Improved, DHC-N01N, NanoEn Tek Inc., Pleasanton, CA, USA).

\subsection{L-Dopa Reaction}

To evualuate the function of melanin synthesis in cultured melanocytes, after the indiated treatments, cells were incubated with $0.1 \%(w / v)$ levodopa (L-dopa) (Wako) for $1 \mathrm{~h}$ at $37{ }^{\circ} \mathrm{C}$ in an atmosphere containing $5 \%(v / v) \mathrm{CO}_{2}$. The cells were then photographed under bright-field microscopy (Biozero 8000, Keyence Co., Osaka, Japan).

\subsection{Trosinase Activity Assay}

The activity of tyrosinase in cultured melanocytes was measured using the Tyrosinase Activity Assay Kit (ab25899; Abcam, Tokyo, Japan) after the indicated treatments. Briefly, melanocytes $\left(5 \times 10^{5}\right.$ cells) were homogenized with $500 \mu \mathrm{L}$ of ice-cold Tyrosinase Assay buffer to perform lysis and kept on ice for $10 \mathrm{~min}$, and the mixture was centrifuged at $10,000 \times g$ for $15 \mathrm{~min}$ at $4{ }^{\circ} \mathrm{C}$. The tyrosinase activity in the supernatant was determined spectrophotometrically with absorbance at $510 \mathrm{~nm}$ using a Model 680 Microplate Reader (Bio-Rad Laboratories, Hercules, CA, USA), according to the manufacturer's protocol. 


\subsection{RNA Isolation and Real-Time RT-PCR Analysis}

Total RNA from cell pellets was isolated using a Maxwell ${ }^{\circledR} 16$ LEV simplyRNA Tissue Kit (Promega, Madison, WI, USA), following the manufacturer's instructions. RNA integrity was verified by gel electrophoresis. Total RNA (100 ng) was reversetranscribed into first-strand cDNA (ReverTra Ace ${ }^{\circledR}$ qPCR RT Master Mix; TOYOBO, Osaka, Japan). The primers used for real-time PCR were as follows: hTYR, sense $5^{\prime}$ TGACTCCAATTAGCCAGTTCCT- ${ }^{\prime}{ }^{\prime}$ and antisense $5^{\prime}$-GACAGCATTCCTTCTCCATCAG$3^{\prime}$; and hTYRP1, sense $5^{\prime}$-CTCAATGGCGAGTGGTCTGT- $3^{\prime}$ and antisense $5^{\prime}$-TTCCAAGCACTGAGCGACAT- $3^{\prime}$. Real-time PCR was conducted using a QuantStudio ${ }^{\circledR} 5$ Real-time PCR System (Applied Biosystems, CA, USA). Reactions were run in triplicate, during three independent experiments. The geometric mean of the housekeeping gene, GAPDH, was used as an internal control to normalize variability in expression levels.

\subsection{Oxidative Stress Assessment}

For cultured HEMn-MPs, oxidative stress was detected by live imaging using CellROX ${ }^{\circledR}$ Green Reagent (\#C10444; Thermo Fisher Scientific Inc.). Cells were treated with $5 \mu \mathrm{M}$ CellROX ${ }^{\circledR}$ Green Reagent for $30 \mathrm{~min}$ and then washed with PBS twice, treated with various concentrations of Sanqi-CK, and subsequently subjected to live-cell imaging by phasecontrast and confocal fluorescence microscopy (Biozero 8100; Keyence Co., Osaka, Japan). Hoechst 33342 (1:500 dilution; Invitrogen) was used to stain nuclei.

\subsection{Measurement of Reduced and Oxidized Glutathione}

Reduced glutathione (GSH) and oxidized glutathione (GSSG) levels in melanocytes were measured using the GSSG/GSH quantification kit (\#G257; Dojindo Molecular Technologies Inc., Kumamoto, Japan) after the indicated treatments. Briefly, melanocytes $\left(1 \times 10^{7}\right.$ cells) were homogenized with $80 \mu \mathrm{L}$ of $10 \mathrm{mmol} / \mathrm{L} \mathrm{HCl}$ and $20 \mu \mathrm{L}$ of $5 \%(v / v)$ 5 -sulfosalicylic acid, and the mixture was centrifuged at $8000 \times \mathrm{g}$ for $10 \mathrm{~min}$ at $4{ }^{\circ} \mathrm{C}$. Total glutathione and GSSG levels in the supernatant were determined spectrophotometrically using a Model 680 Microplate Reader (Bio-Rad Laboratories, Hercules, CA, USA), according to the manufacturer's protocol. Concentrations of total glutathione and GSSG were determined using standard curves. GSH levels were calculated using the following formula: GSH $(\mu \mathrm{mol} / \mathrm{L})=$ total glutathione $(\mu \mathrm{mol} / \mathrm{L})-2 \times$ GSSG $(\mu \mathrm{mol} / \mathrm{L})$. The GSH $/$ GSSG ratio was then calculated.

\subsection{Measurement of Glutathione Reductase Activity}

Glutathione reductase (GR) activity in melanocytes was measured after the indicated treatments, using a Glutathione Reductase Assay Kit (ab83461; Abcam, Tokyo, Japan), according to the manufacturer's instructions. Briefly, melanocytes $\left(1 \times 10^{6}\right.$ cells $)$ were homogenized with $150 \mu \mathrm{L}$ of cold GR Assay Buffer, and the mixture was centrifuged at $10,000 \times g$ for $15 \mathrm{~min}$ at $4{ }^{\circ} \mathrm{C}$. The supernatant was collected for assay. The absorbance was read at $405 \mathrm{~nm}$ in a Model 680 Microplate Reader (Bio-Rad Laboratories) to calculate the activity.

\subsection{Animals and In Vivo Experimental Procedures}

Three male 7-week-old JY-4 black guinea pigs were purchased from Tokyo Laboratory Animals Science (Tokyo, Japan) and maintained under specific pathogen-free conditions. In each guinea pig, four areas (each $2 \mathrm{~cm} \times 2 \mathrm{~cm}$ ) of the dorsal skin were used for four different experimental groups after clipping the hair with an electric shaver. Every experimental group contained three guinea pigs. The animals were treated topically with $20 \%(w / v)$ rhododendrol daily for 21 days to induce skin depigmentation and concomitantly given topical vehicle ointment or Sanqi-CK ointment $(2 \%)$ daily for 21 days. Samples of skin were collected $24 \mathrm{~h}$ after the final treatment. Every effort was made to minimize animal suffering. The study was conducted according to the Guiding Principles for the Care and 
Use of Laboratory Animals and approved by the Committee for Animal Experiments at Osaka City University (Permit No. 18042, Osaka, Japan).

\subsection{Measurement of Skin Color}

Skin coloration in the treated area was quantified using a portable reflectance spectrophotometer (Konica CM-26d; Konica Minolta, Tokyo, Japan). The results are expressed as an $L^{*}$ value, which is a measure of skin lightness on a continuous black to white scale $(0=$ completely black; $100=$ completely white $)$.

\subsection{Fontana-Masson Staining}

Dorsal skin tissues were fixed in a 10\% formalin neutral buffer solution (Wako Pure Chemicals, Osaka, Japan), embedded in paraffin, and sectioned on a microtome at a thickness of $5 \mu \mathrm{m}$. The sections were deparaffinized with xylene, rehydrated with a graded series of ethanol, and then subjected to Fontana-Masson staining using the Fontana-Masson Stain Kit (ab150669; Abcam), according to the manufacturer's instructions.

\subsection{Fluorescent Immunohistochemical Staining of Melanocytes}

Dorsal skin tissues were fixed in $10 \%$ formaldehyde and embedded in paraffin, after which $5 \mu \mathrm{m}$ sections were used for fluorescent immunohistochemical staining. Sections were incubated overnight at $4{ }^{\circ} \mathrm{C}$ with primary antibodies specific for tyrosine-related protein-1 (TYRP1) (HPA000937, 1:200 dilution; Sigma, St. Loius, MO, USA), and then incubated with the secondary antibody (anti-rabbit IgG Alex Fluor 488; Invitrogen, Thermo Fisher Scientific, Loughborough, United Kingdom) [21]. Sections were counterstained with Hoechst 33342 at a ratio of 1:500 (Invitrogen). The stained sections were visualized using a light microscope or a Biozero 8100 confocal microscope (Keyence Co., Osaka, Japan).

\subsection{Statistical Analyses}

All experiments were repeated at least three times. Data are presented as mean \pm SD. Statistical analyses were conducted using two-way analysis of variance to assess interactions between variables. Unpaired Student's $t$-test (Microsoft Excel; Microsoft Corp., Redmond, WA, USA) was used to compare differences between two different groups. $p$-values $<0.05$ were considered statistically significant.

\section{Results}

\subsection{Sanqi-CK Attenuates $\mathrm{H}_{2} \mathrm{O}_{2}$-Induced Cytotoxicity in Human Primary Epidermal Melanocytes}

To investigate the effects of Sanqi-CK (Figure 1b) on the morphology of melanocytes, cultured normal human primary epidermal melanocytes (HEMn-MPs) were treated with various concentrations of Sanqi-CK $(0.1-100 \mu \mathrm{g} / \mathrm{mL})$ for $24 \mathrm{~h}$, after which changes in morphology were observed via bright-field microscopy. No significant effects on melanocyte morphology were observed up to $2.5 \mu \mathrm{g} / \mathrm{mL}$ of Sanqi-CK; beyond this concentration, cytotoxicity was evident (Figure 1a). Furthermore, cell viability was determined using a 3-[4-dimethylthiazol-2-yl]-2,5-diphenyltetrazolium bromide (MTT) assay. Sanqi-CK up to $2.5 \mu \mathrm{g} / \mathrm{mL}$ did not affect viability, whereas viability decreased significantly above this concentration (Figure 1c). These results suggest that Sanqi-CK is nontoxic over a wide range of concentrations. A Sanqi-CK concentration of $1.25 \mu \mathrm{g} / \mathrm{mL}$ was chosen for subsequent experiments because this concentration demonstrated no effects on cell viability.

To investigate the effects of Sanqi-CK on the survival of melanocytes under oxidative stress, HEMn-MPs were treated with $1.25 \mu \mathrm{g} / \mathrm{mL}$ Sanqi-CK for $6 \mathrm{~h}$ and then exposed to $0.4 \mathrm{mM} \mathrm{H}_{2} \mathrm{O}_{2}$ for $24 \mathrm{~h}$, after which morphology (Figure $2 \mathrm{a}, \mathrm{b}$ ) and viability (Figure $2 \mathrm{c}$ ) of the cells were assessed. Morphologic observations with light microscopy showed that exposure of melanocytes to $0.4 \mathrm{mM} \mathrm{H}_{2} \mathrm{O}_{2}$ for $24 \mathrm{~h}$ resulted in membrane blebbing and cell shrinkage (Figure 2a, middle panel); these changes were rescued by pretreatment with $1.25 \mu \mathrm{g} / \mathrm{mL}$ Sanqi-CK (Figure 2a, right panel). Cell staining with ethidium bromide (for dead cells) and Hoechst 33342 (for both live and dead cells) showed that dead cells strikingly increased 
after $24 \mathrm{~h}$ treatment with $0.4 \mathrm{mM} \mathrm{H}_{2} \mathrm{O}_{2}$, whereas Sanqi-CK pretreatment reversed this $\mathrm{H}_{2} \mathrm{O}_{2}$-induced cell death (Figure $2 \mathrm{~b}$ ). The protective effects of Sanqi-CK against $\mathrm{H}_{2} \mathrm{O}_{2}$ were likewise confirmed using the MTT assay. The viability of HEMn-MPs decreased to 57.6\% of control when subjected to $0.4 \mathrm{mM} \mathrm{H}_{2} \mathrm{O}_{2}$, but preincubation with Sanqi-CK for $6 \mathrm{~h}$ reduced these cytotoxic effects of $0.4 \mathrm{mM} \mathrm{H}_{2} \mathrm{O}_{2}$ (Figure 2c).

(a)

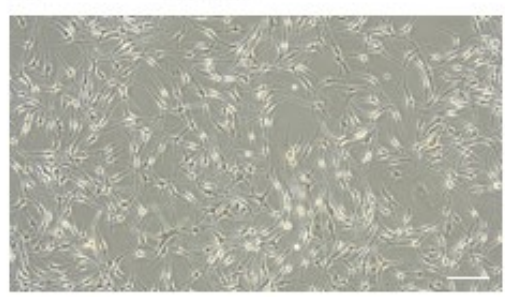

(b)

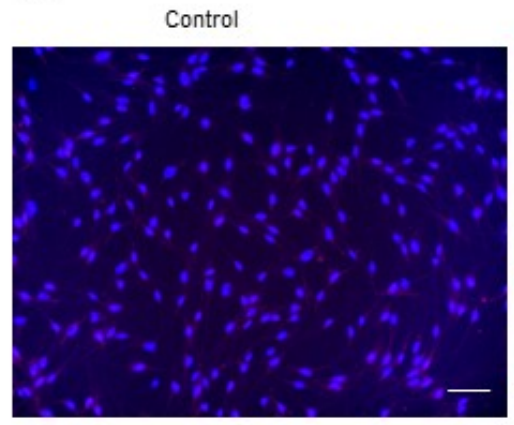

(c)

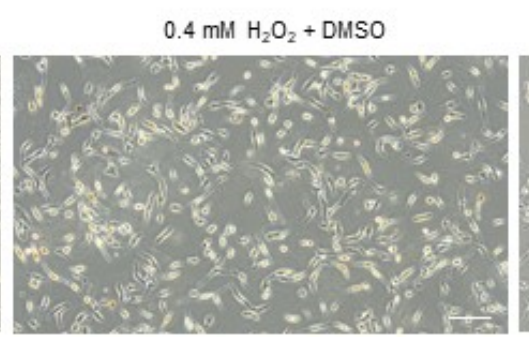

$0.4 \mathrm{mM} \mathrm{H} \mathrm{O}_{2}+$ DMSO

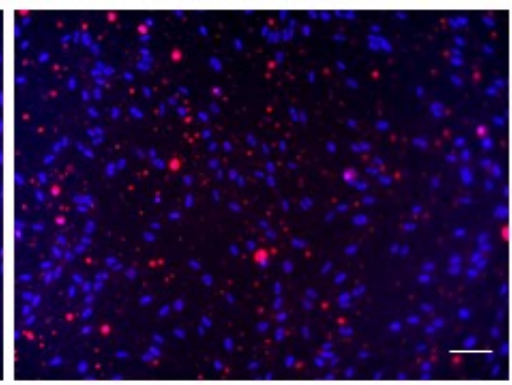

$-$
Red: Ethidium Bromide (dead cells)

Blue: Hoechst 33342 (live and dead cells)

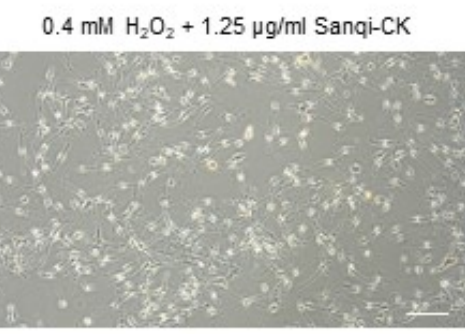

$0.4 \mathrm{mM} \mathrm{H} \mathrm{O}_{2}+1.25 \mu \mathrm{g} / \mathrm{ml}$ Sanqi-CK

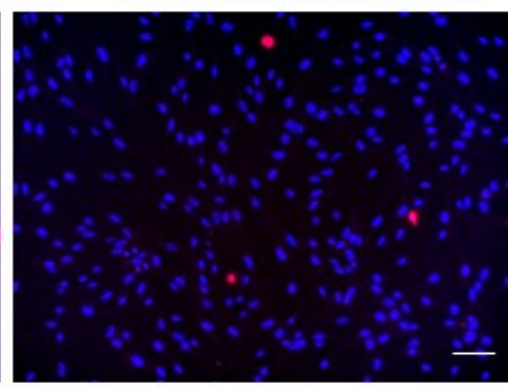

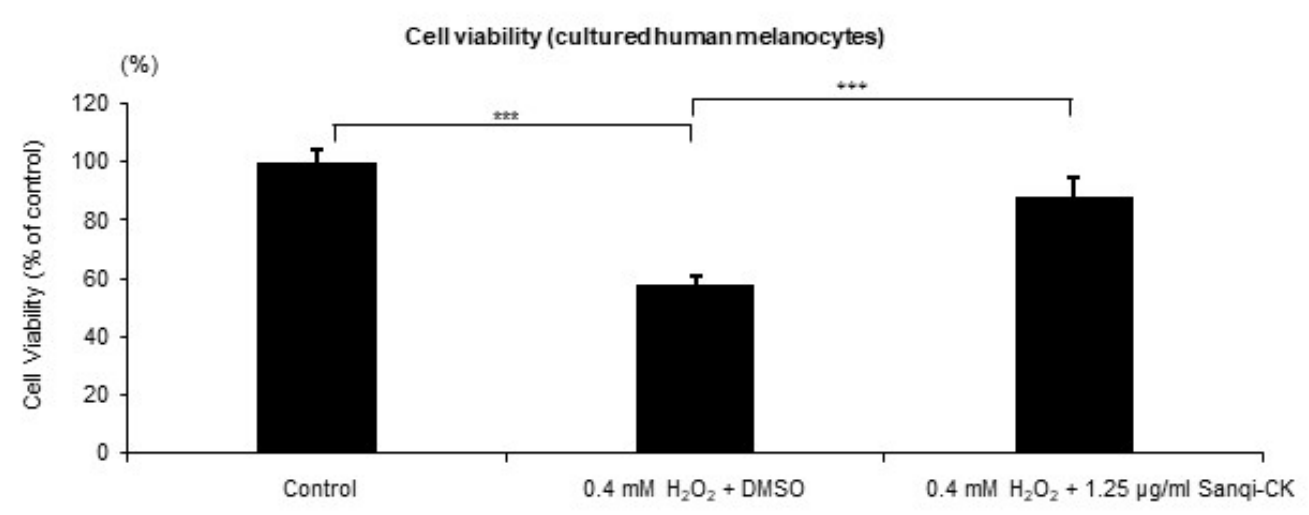

Figure 2. Protective effects of Sanqi-CK on cell survival of cultured human epidermal melanocytes (HEMn-MPs) against $\mathrm{H}_{2} \mathrm{O}_{2}$ treatment. The cells were pretreated with a nontoxic concentration of Sanqi-CK $(1.25 \mu \mathrm{g} / \mathrm{mL})$ for $6 \mathrm{~h}$, followed by $0.4 \mathrm{mM} \mathrm{H}_{2} \mathrm{O}_{2}$ treatment for an additional $24 \mathrm{~h}$. After these treatments, (a) melanocyte morphology was observed with bright-field microscopy; (b) cell staining was performed with ethidium bromide (red) and Hoechst 33342 (blue) and observed using confocal fluorescence microscopy; and (c) cell viability was evaluated by the MTT assay. White bar in $(\mathbf{a}, \mathbf{b}), 50 \mu \mathrm{m}$. Data in (c) represent the results of three independent experiments and are shown as mean $\pm \mathrm{SD}$. ${ }^{* * *} p<0.01$; difference between the indicated two groups by Student's $t$-test.

\subsection{Sanqi-CK Attenuates $\mathrm{H}_{2} \mathrm{O}_{2}$-Induced Suppression of Melanogenesis in Human Primary Epidermal Melanocytes}

To investigate the effects of Sanqi-CK on the function of melanocytes under oxidative stress, the melanin content, L-dopa reaction, tyrosinase activity assay, and mRNA expression levels of key genes involved in melanogenesis were evaluated. HEMn-MPs were pretreated for $6 \mathrm{~h}$ with $1.25 \mu \mathrm{g} / \mathrm{mL}$ Sanqi-CK and then exposed to chronic oxidative 
stress by incubation with $0.2 \mathrm{mM} \mathrm{H}_{2} \mathrm{O}_{2}$ for 5 days. At the end of 5 days, cells exposed to $0.2 \mathrm{mM} \mathrm{H}_{2} \mathrm{O}_{2}$ were markedly less pigmented than control cells, and Sanqi-CK pretreatment markedly improved the culture medium color (Figure 3a). Melanin content was quantified using the melanin content assay of cell lysates (Figure 3b) and the culture medium supernatant (Figure 3c) of cultured HEMn-MPs. The results showed that chronic oxidative stress significantly decreased melanin content (Figure 3b,c), and Sanqi-CK pretreatment significantly attenuated $\mathrm{H}_{2} \mathrm{O}_{2}$-induced suppression of melanogenesis in both the culture medium and cell lysates (Figure $3 b, c$ ).

The function of melanin synthesis was further evaluated by the darkness of cultured melanocytes after adding L-dopa as a substrate [22]. After 5-day exposure to $0.2 \mathrm{mM}$ $\mathrm{H}_{2} \mathrm{O}_{2}$, the L-dopa reaction was performed (Figure 3d). Cells treated with $0.2 \mathrm{mM} \mathrm{H}_{2} \mathrm{O}_{2}$ exhibited markedly poor reactions to L-dopa, as they were less pigmented than control cells. Sanqi-CK pretreatment greatly improved the response to L-dopa (Figure 3d). Furthermore, after HEMn-MPs were pretreated for $6 \mathrm{~h}$ with Sanqi-CK and then exposed to $0.2 \mathrm{mM}$ $\mathrm{H}_{2} \mathrm{O}_{2}$ for $24 \mathrm{~h}$, the activity of the melanogenesis key enzyme tyrosinase was evaluated by tyrosinase activity assay (Figure $3 \mathrm{e}$ ), and the expression levels of the key melanogenesisrelated genes (TYR and TYRP1) were evaluated by real-time PCR analysis (Figure 3f,g). Tyrosinase activity and mRNA expression levels of both genes were significantly decreased in cells treated with $0.2 \mathrm{mM} \mathrm{H}_{2} \mathrm{O}_{2}$, compared with control cells, and Sanqi-CK pretreatment significantly inhibited $\mathrm{H}_{2} \mathrm{O}_{2}$-induced reduction of tyrosinase activity (Figure 3 e) and $\mathrm{H}_{2} \mathrm{O}_{2}$ induced reduction of $T Y R$ and TYRP1 expression (Figure 3f,g). These results therefore suggest that Sanqi-CK pretreatment can improve the dysfunction of melanocytes induced by chronic oxidative stress.

\subsection{Sanqi-CK Reduces $\mathrm{H}_{2} \mathrm{O}_{2}$-Induced Oxidative Stress in Human Primary Epidermal Melanocytes}

Next, we examined whether Sanqi-CK protected melanocytes against oxidative stress. The effects of Sanqi-CK on oxidative stress were measured in cultured melanocytes treated with $\mathrm{H}_{2} \mathrm{O}_{2}$. CellROX ${ }^{\circledR}$ Green Reagent was used to visualize intracellular oxidative stress in melanocytes by green fluorescence. As shown in Figure 4, exposing HEMn-MPs to $0.4 \mathrm{mM}$ $\mathrm{H}_{2} \mathrm{O}_{2}$ for $24 \mathrm{~h}$ produced an obvious increase in green fluorescence. $\mathrm{H}_{2} \mathrm{O}_{2}$-induced green fluorescence was markedly attenuated in cells pretreated with $1.25 \mu \mathrm{g} / \mathrm{mL}$ Sanqi-CK for $6 \mathrm{~h}$ (Figure $4 \mathrm{a}, \mathrm{b}$ ), demonstrating the attenuating effects of Sanqi-CK on oxidative stress in melanocytes.

\subsection{Sanqi-CK Modulates Redox Balance and Activates Glutathione Reductase in $\mathrm{H}_{2} \mathrm{O}_{2}$-Treated Human Primary Epidermal Melanocyte}

To further explore underlying mechanisms of the effects of Sanqi-CK in reducing oxidative stress, we also assessed whether Sanqi-CK treatment modulates the major antioxidant defense mechanism in melanocytes. The glutathione redox cycle plays a key role in the reduction of intracellular hydroperoxides. Glutathione is one of the most widely studied antioxidants synthesized in the body and prevents oxidative stress by removing ROS. Glutathione is usually present in reduced form (GSH), but GSH is converted to its oxidized form (GSSG) during oxidative stress, and the GSH/GSSG ratio has been used as an indicator of oxidative stress [23]. Hence, we estimated the effects of Sanqi-CK on the GSH/GSSG ratio and observed a significant decrease in this ratio in $\mathrm{H}_{2} \mathrm{O}_{2}$-treated melanocytes (Figure 5a). In contrast, Sanqi-CK pretreatment prevented $\mathrm{H}_{2} \mathrm{O}_{2}$-mediated reduction of the GSH/GSSG ratio (Figure 5a), thereby indicating that Sanqi-CK maintained a well-regulated redox balance.

GR catalyzes the conversion of GSSG to GSH and is a pivotal enzyme in the cellular antioxidant defense mechanism. It plays a key role in response to oxidative stress by maintaining the intracellular pool of GSH [23]. We observed a significant decrease in GR activity in melanocytes after $24 \mathrm{~h}$ of $\mathrm{H}_{2} \mathrm{O}_{2}$ treatment (Figure $5 \mathrm{~b}$ ), which was rescued by Sanqi-CK pretreatment (Figure $5 b$ ). 
(a)

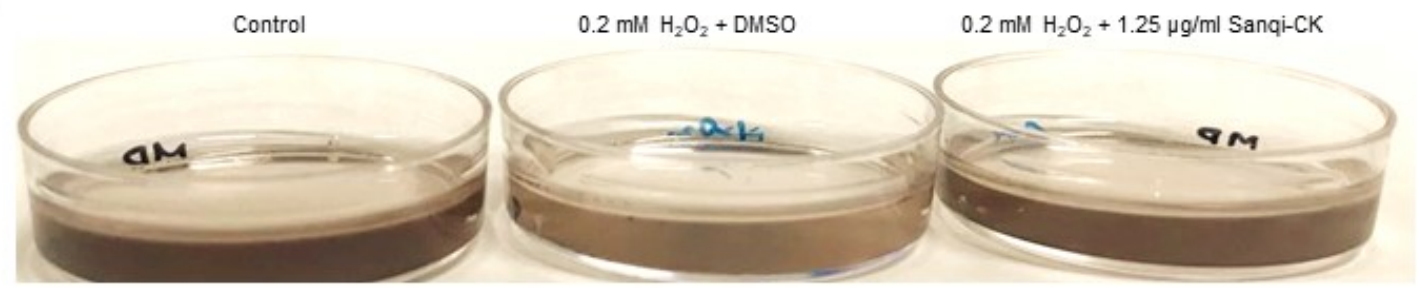

(b)

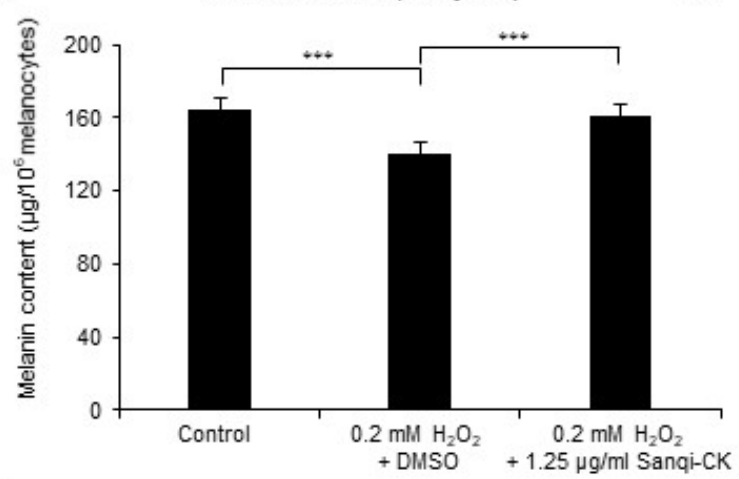

(d)

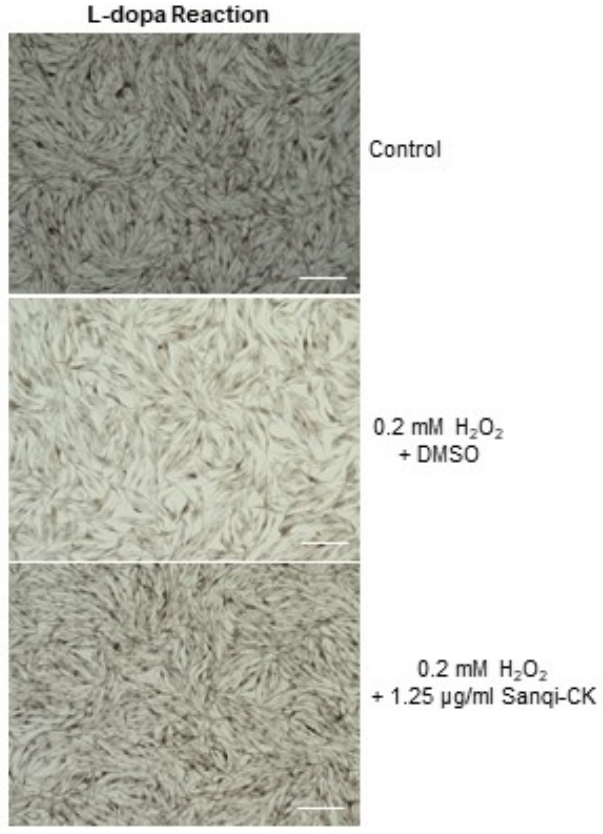

(f)

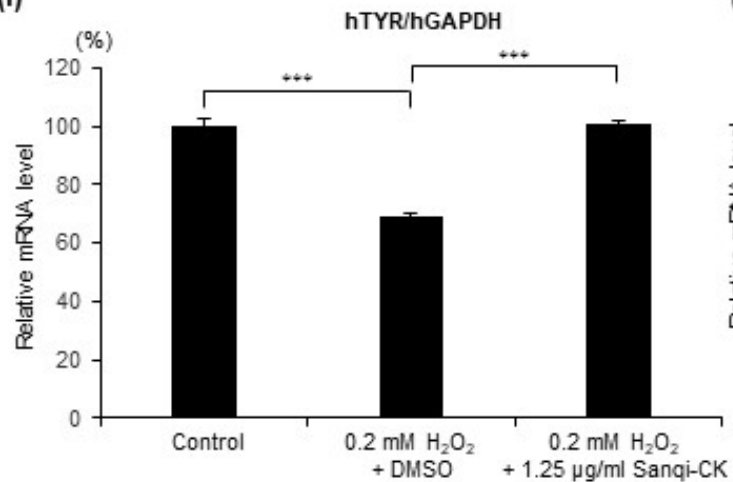

(e)
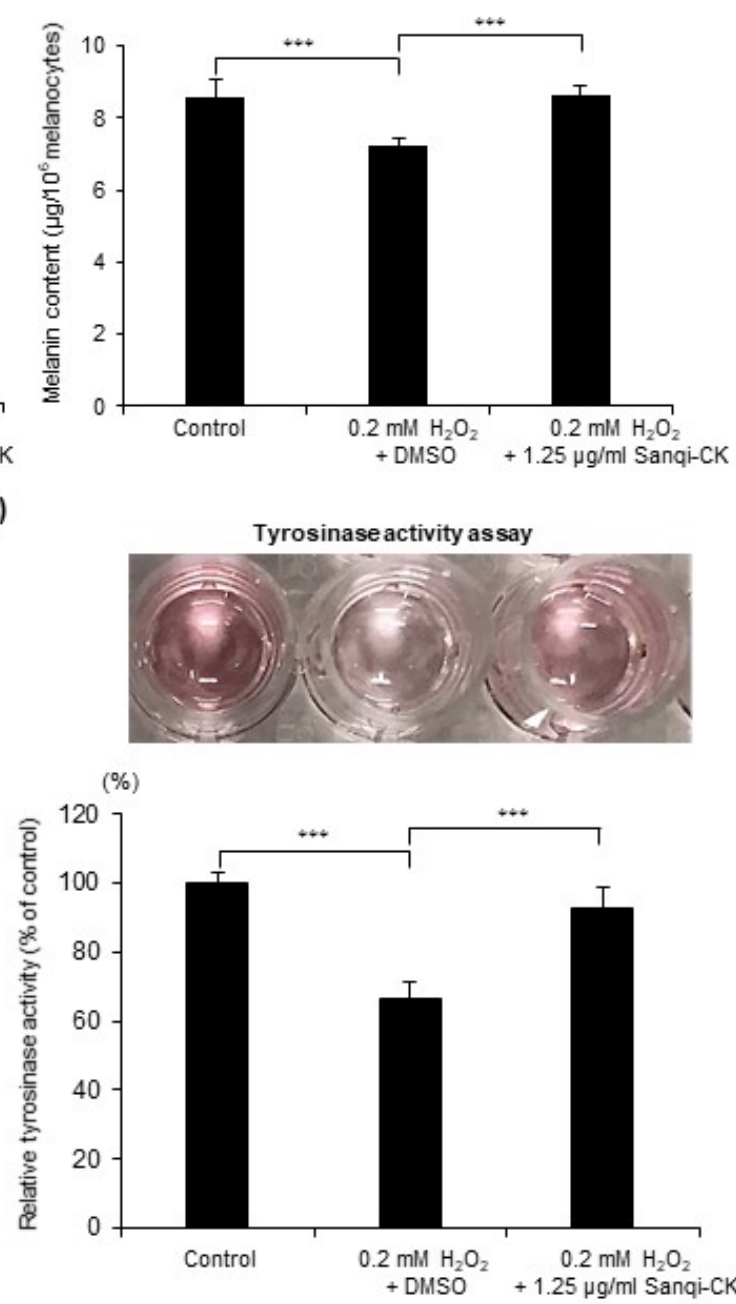

(g)

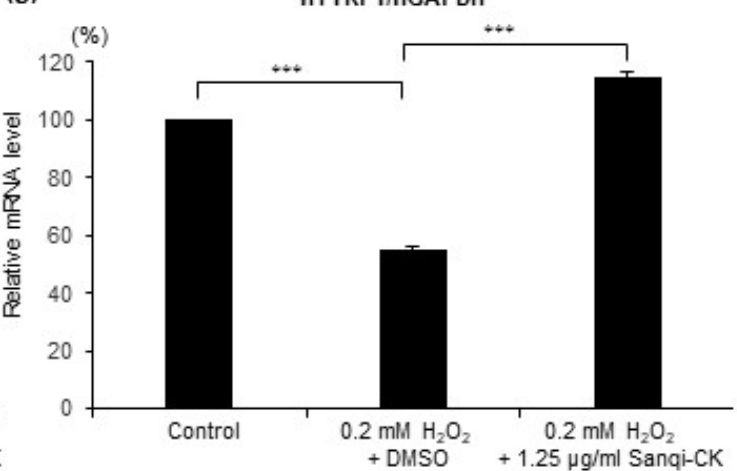

Figure 3. Protective effects of Sanqi-CK on melanin synthesis of cultured HEMn-MPs against $\mathrm{H}_{2} \mathrm{O}_{2}$ treatment. Melanocytes were pretreated with a nontoxic concentration of Sanqi-CK $(1.25 \mu \mathrm{g} / \mathrm{mL})$ for $6 \mathrm{~h}$ and then exposed to $0.2 \mathrm{mM} \mathrm{H}_{2} \mathrm{O}_{2}$ for 5 days. At the end of these treatments, (a) cultured melanocytes in medium were photographed; melanin content was quantified by melanin content assay in (b) cell lysates and (c) the culture medium; and (d) the L-dopa reaction was performed, with changes 
in pigmentation observed under bright-field microscopy. White bar in (d), $50 \mu \mathrm{m}$. At $24 \mathrm{~h}$ after exposure to the indicated treatments, tyrosinase activity (e) was evaluated by tyrosinase activity assay, the expression levels of key melanogenesisrelated genes TYR (f) and TYRP1 (g) were evaluated by real-time PCR analysis, with normalization to GAPDH expression. Data in $(\mathbf{b}, \mathbf{c}, \mathbf{e}-\mathbf{g})$ represent the results of three independent experiments and are shown as mean \pm SD. ${ }^{* * *} p<0.01$; difference between the indicated two groups by Student's $t$-test.

\subsection{Topical Sanqi-CK Ointment Treatment Suppresses Rhododendrol-Induced Depigmentation in Guinea Pigs}

Rhododendrol was previously used as a skin-whitening cosmetic, but it was withdrawn from the market in 2013 because it causes a depigmentation disorder. A previous report suggested that the toxicity of rhododendrol towards melanocytes is the result of the production of cytotoxic ROS [24]. Moreover, topical rhododendrol has been used to develop animal models of leukoderma in keratin 14-promoter driven, stem cell factor transgenic (K14-SCF) mice [25,26] and guinea pigs [27].

To confirm the protective effects of Sanqi-CK in vivo, we investigated whether topical Sanqi-CK treatment could protect melanocytes against rhododendrol-induced cytotoxicity and suppress rhododendrol-induced leukoderma development in black guinea pigs (Strain: JY-4) (Figure 6a). After daily topical application of 20\% rhododendrol for 21 days, obvious skin depigmentation was observed; however, concomitant administration of $2 \%$ Sanqi-CK ointment markedly suppressed this rhododendrol-induced depigmentation (Figure $6 \mathrm{~b}$ ). In the areas where vehicle ointment was applied (instead of Sanqi-CK), topical 20\% rhododendrol induced a significant increase in skin lightness, as determined by the skin color L* value (Figure 6c). However, the rhododendrol-induced increase in skin lightness was significantly suppressed in areas treated with topical Sanqi-CK (Figure 6c). Further, Fontana-Masson staining for melanin showed that topical Sanqi-CK treatment markedly attenuated rhododendrol-induced decreases in melanin content in rhododendrolapplied skin (Figure 6d). Histochemical immunostaining of epidermal melanocytes with anti-TYRP1 antibody, a standard marker for melanocytes (Figure 6e), revealed complete disappearance of melanocytes after 21 days of rhododendrol topical application. In contrast, topical Sanqi-CK treatment rescued the disappearance of melanocytes in the epidermis of guinea pig skin (Figure 6e,f). 
(a) CellROX Green Reagentfor oxidative stress detection

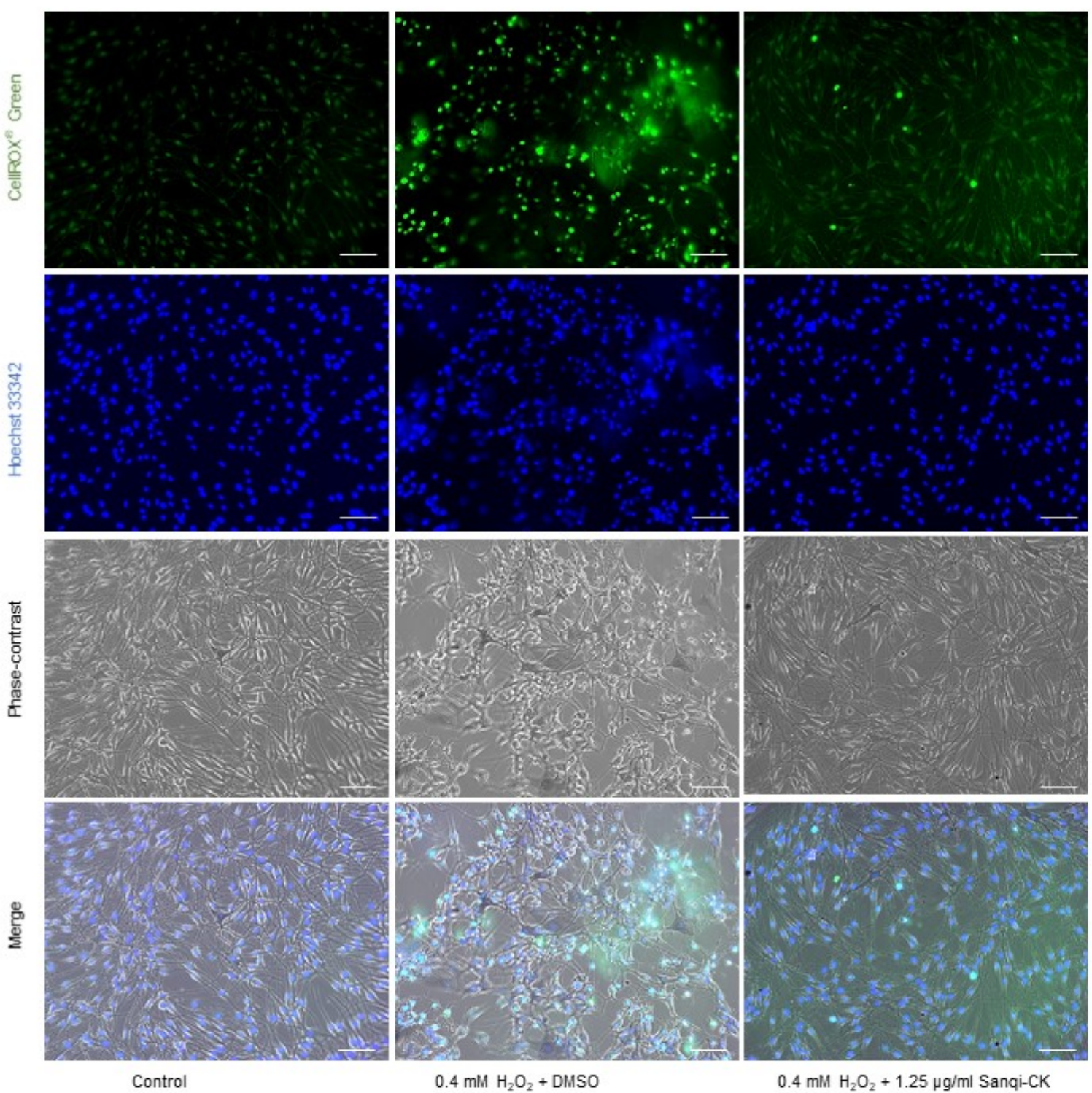

(b)

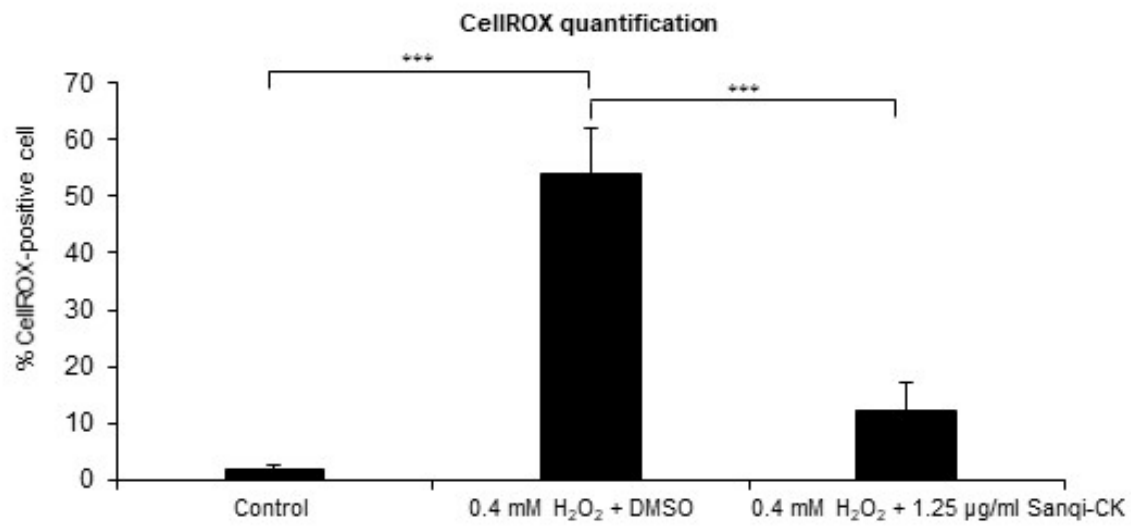

Figure 4. Effects of Sanqi-CK on oxidative stress in cultured human epidermal melanocytes (HEMn-MPs). The cells were pretreated with a nontoxic concentration of Sanqi-CK $(1.25 \mu \mathrm{g} / \mathrm{mL})$ for $6 \mathrm{~h}$, followed by $0.4 \mathrm{mM} \mathrm{H}_{2} \mathrm{O}_{2}$ treatment for an additional $24 \mathrm{~h}$. Oxidative stress in cultured cells was detected by CellROX ${ }^{\circledR}$ Green reagent after exposure to the indicated treatments for $24 \mathrm{~h}$. Nuclei were stained blue by Hoechst 33342. The cultured cells were photographed by phase-contrast and confocal fluorescence microscopy (a). Representative images obtained in three independent experiments are shown. White 
bar, $50 \mu \mathrm{m}$. Green signals indicate the presence of oxidative stress in cells. Percentage of CellROX-positive cells was quantified on 10 random fields per treatment group (b). All experiments were repeated at least three times and data presented in $(\mathbf{b})$ are shown as mean $\pm \mathrm{SD} .{ }^{* * *} p<0.01$; difference between the indicated two groups by Student's $t$-test.

(a)

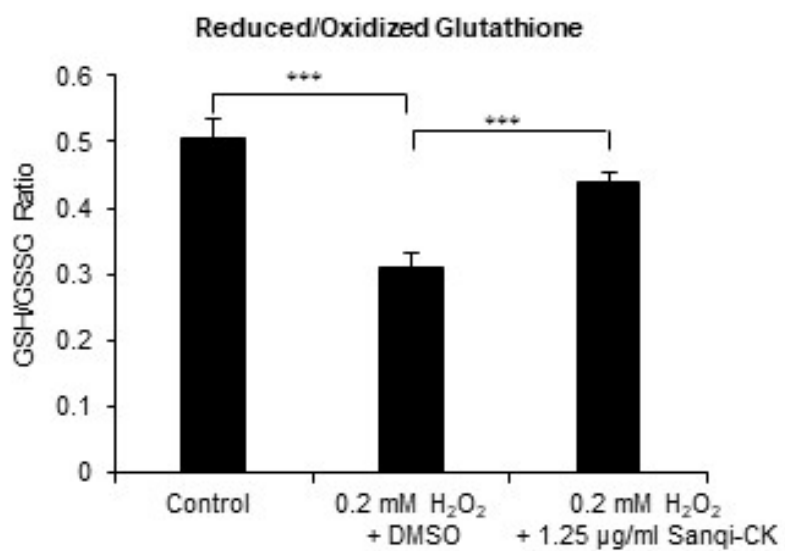

(b)
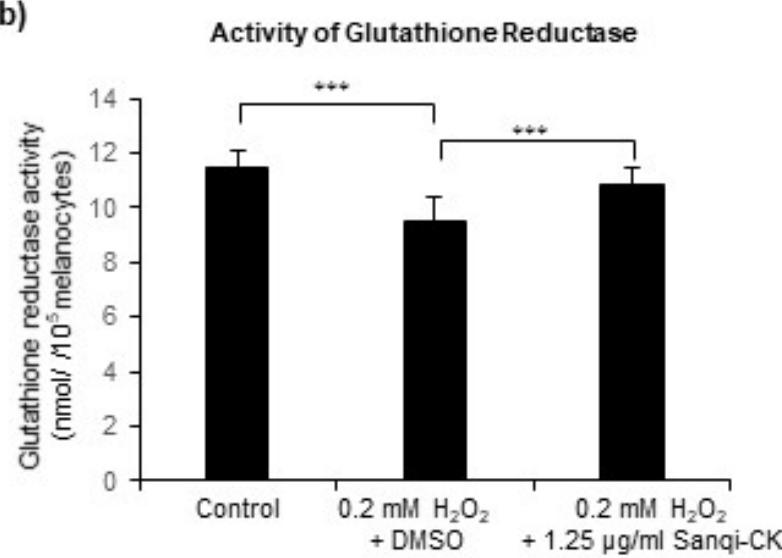

Figure 5. Effects of Sanqi-CK on redox status in cultured human epidermal melanocytes (HEMn-MPs). The cells were pretreated with a nontoxic concentration of Sanqi-CK $(1.25 \mu \mathrm{g} / \mathrm{mL})$ for $6 \mathrm{~h}$, followed by $0.2 \mathrm{mM} \mathrm{H}_{2} \mathrm{O}_{2}$ treatment for an additional $24 \mathrm{~h}$. After these treatments, we determined the (a) reduced glutathione/oxidized glutathione (GSH/GSSG) ratio and $(\mathbf{b})$ glutathione reductase activity in the cells. Data in $(\mathbf{a}, \mathbf{b})$ represent the results of three independent experiments and are shown as mean $\pm \mathrm{SD}$. ${ }^{* * *} p<0.01$; difference between the indicated two groups by Student's $t$-test.

(a)

\section{Experimental Schedule}

(Experimental Model: JY-4 Guinea pig, $n=3 /$ group)

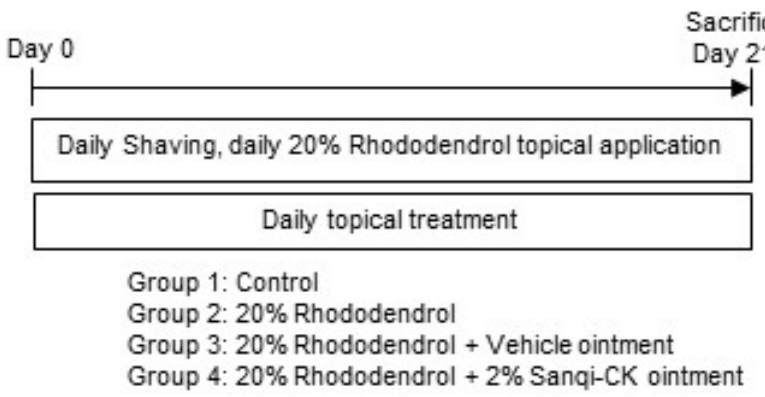

(c)

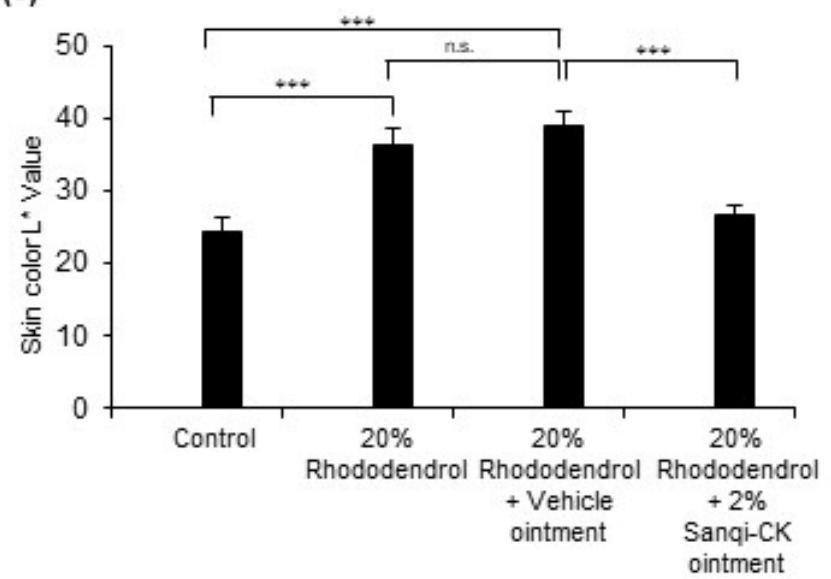

(b)

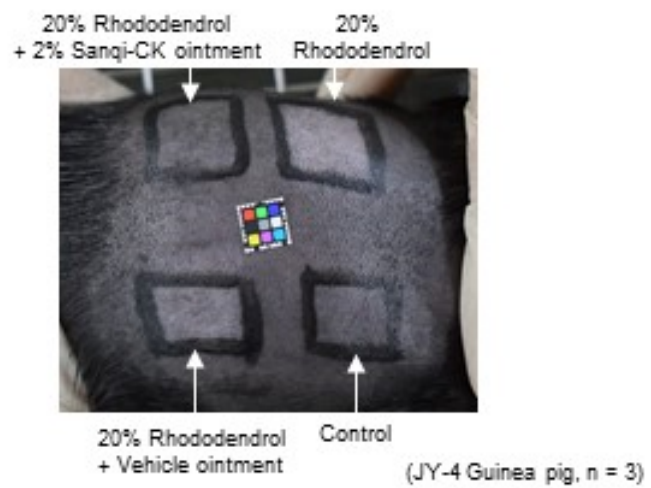

(d)

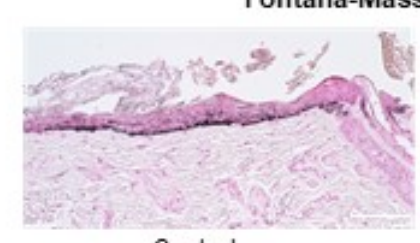

Control

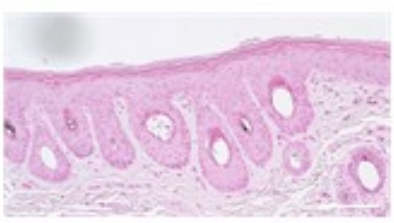

$20 \%$ Rhododendrol + Vehicle ointment
$20 \%$ Rhododendrol

(JY-4 Guinea pig, $\mathrm{n}=3$ )

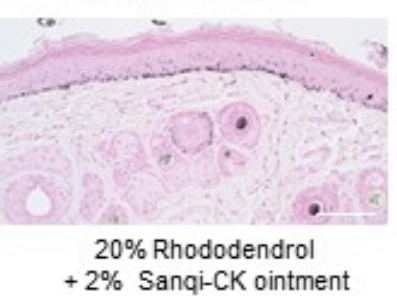

Figure 6. Cont. 
(e) Immunofluorescence Staining (FFPE sections; Anti-TYRP1)
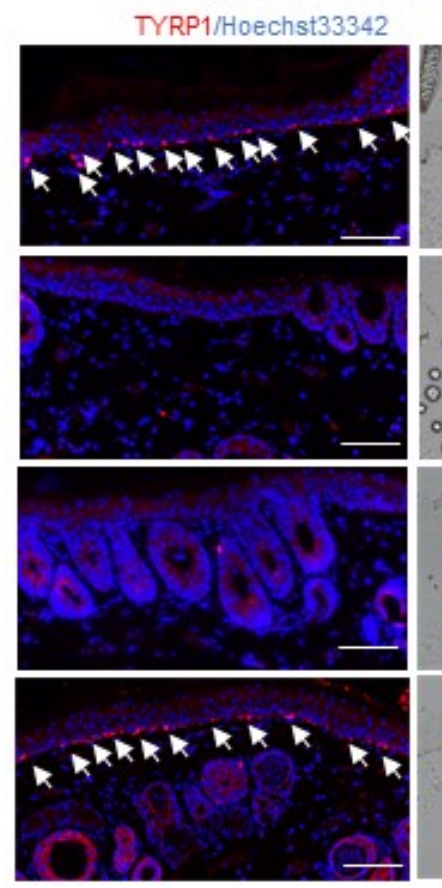

Bright-field Image

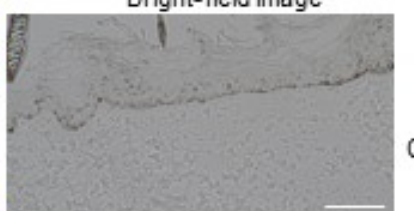

Control
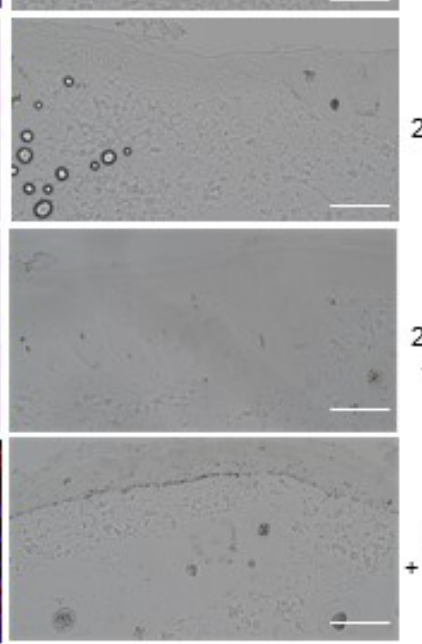

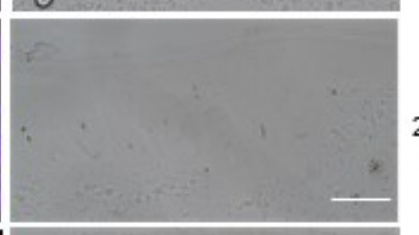

(f)

\section{Epidermal melanocytes quantification}

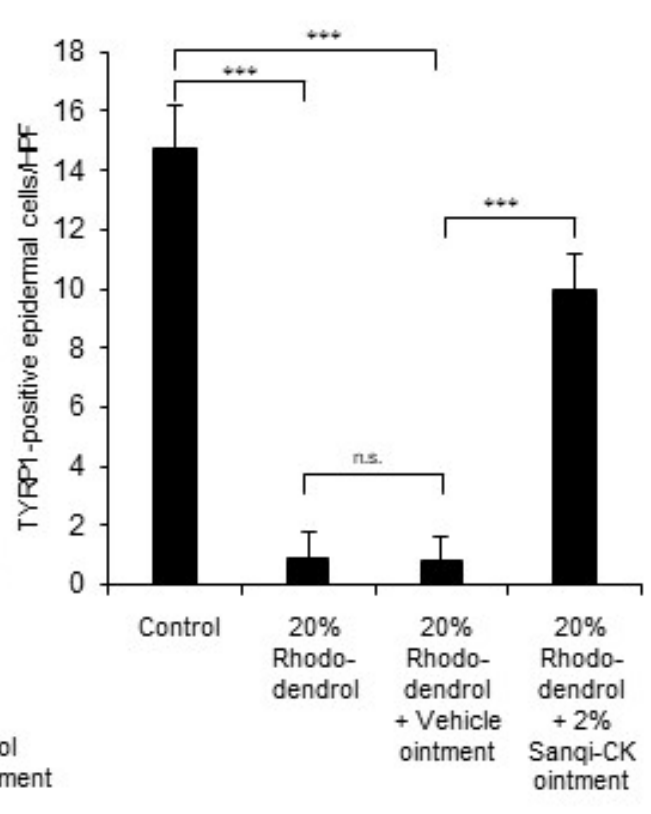

Figure 6. Effects of Sanqi-CK ointment in a rhododendrol-induced leukoderma guinea pig model. (a) Experimental schedule; (b) macroscopic appearance of skin color; (c) $\mathrm{L}^{*}$ value of skin color in the indicated treatment groups; (d) Fontana-Masson staining of skin sections in the indicated treatment groups, with melanin appearing black; and (e) melanocytes stained with anti-TYRP1 antibody (in red) and nuclei stained with Hoechst 33342 (in blue), with bright-field images shown in the lower panel. White arrows indicate TYRP1-positive epidermal melanocytes. The red signal outside the skin is from keratin autofluorescence. Representative images of three independent experiments performed are shown in $(\mathbf{b}, \mathbf{d}, \mathbf{e})$. White bar in (d,e), $100 \mu \mathrm{m}$; (f) TYRP1-positive epidermal melanocytes were counted in 10 non-contiguous random grids under high-power magnification fields (HPF, 200×) by confocal microscopy. The number of epidermal melanocytes per 10 hyper-power microscopic fields is shown in the histogram. Data in $(\mathbf{c}, \mathbf{f})$ are shown as mean \pm SD. n.s., no significant difference; ${ }^{* * *} p<0.01$; difference between the indicated two groups by Student's $t$-test.

\section{Discussion}

This study was the first to demonstrate that Sanqi-CK can protect human melanocytes from $\mathrm{H}_{2} \mathrm{O}_{2}$-induced cell damage by modulating redox balance between GSH and GSSG and by activating GR activity. In addition, topical treatment with $2 \%$ Sanqi-CK ointment markedly suppressed rhododendrol-induced skin depigmentation in guinea pigs. Oxidative stress has been demonstrated to play a major role in melanocyte damage, which leads to loss of functional melanocytes in vitiligo [7]. Therefore, antioxidant-based therapy has evolved as a promising strategy for treating vitiligo, and the search for new agents capable of reducing oxidative stress in melanocytes has become an important research focus.

Plant products are generally considered to be less toxic and less prone to side effects than drugs manufactured by chemical synthesis. The potential therapeutic and preventive benefits of plant-based medications have been the subject of an extensive number of studies, and many natural constituents with significant pharmacologic activity have been uncovered [28]. Sanqi, also known as radix notoginseng (the roots of Panax notoginseng), is a widely used traditional Chinese medicine. This extract from the roots of the herb Sanqi has been used as to reduce blood stasis, decrease bleeding, reduce swelling, and alleviate pain in China for thousands of years [29,30]. In addition, it has been used extensively in medical research or clinical settings for a number of disorders, including hypertension, atherosclerosis, diabetes, acute lung injury, cancer, and cardiovascular diseases. Injections and capsules of Sanqi extract have become commercially available and are widely used in clinical practice $[30,31]$. This agent attracted our attention because Sanqi-CK has been 
recently reported to be beneficial in various oxidative-stress-related conditions. For instance, it was shown to alleviate hypolipidemia-associated oxidative stress in high-fat-fed rats through improving hepatic antioxidant activity via increasing superoxide dismutase levels and glutathione peroxidase activities [18]; protect against nephropathy through significantly reducing oxidative stress [19]; and enhance memory through activating the antioxidant system [20]. However, no previous report examined whether Sanqi-CK can protect melanocytes from oxidative stress. Thus, the purpose of the present study was to evaluate the effects of Sanqi-CK on melanocytes under oxidative stress.

In the present study, $\mathrm{H}_{2} \mathrm{O}_{2}$ was used to induce oxidative stress in cultured human primary melanocytes in vitro, and topical rhododendrol application was used to induce oxidative stress in epidermal melanocytes in vivo. We found that after $24 \mathrm{~h}$ incubation with $0.4 \mathrm{mM} \mathrm{H}_{2} \mathrm{O}_{2}$, cultured normal epidermal human melanocytes displayed a marked increase in oxidative stress (detected by CellROX ${ }^{\circledR}$ staining) and dramatic cytotoxicity. In addition, melanin synthesis was strikingly inhibited after 5 days of $0.2 \mathrm{mM} \mathrm{H}_{2} \mathrm{O}_{2}$ stimulation in these cultured melanocytes. However, treatment with a nontoxic concentration of Sanqi$\mathrm{CK}(1.25 \mu \mathrm{g} / \mathrm{mL})$ clearly attenuated the $\mathrm{H}_{2} \mathrm{O}_{2}$-induced oxidative stress, cytotoxicity, and reduced melanin production. These data therefore suggest that Sanqi-CK pretreatment can reduce the accumulation of oxidative stress and alleviate oxidative-stress-induced loss of function (melanin production) in melanocytes.

We also developed a topical Sanqi-CK ointment and examined the effects of this ointment on skin and melanocytes under oxidative stress. We used a guinea pig model because epidermal melanocytes do not reside in the dorsal skin of mice; black guinea pigs (strain, JY-4) have epidermal melanocytes in their entire body skin. A cosmetic lotion containing rhododendrol was used to produce rhododendrol-induced leukoderma, a depigmentation disorder caused by increased oxidative stress and cell cytotoxicity in melanocytes. Rhododendrol toxicity in melanocytes is known to be prevented by antioxidants [24]. We previously reported the development of this topical-rhododendrol-induced depigmentation animal model in guinea pigs [27], which is recognized as a good animal model for screening antioxidant agents able to protect melanocytes. Twenty-one days of topical 20\% rhododendrol application induced obvious depigmentation, marked reduction in the number of epidermal melanocytes, and marked reduction in melanin pigment in the epidermis. However, topical $2 \%$ Sanqi-CK ointment attenuated rhododendrolinduced melanocyte cell death and skin depigmentation. These results strongly suggest that Sanqi-CK protects against oxidative-stress-induced cytotoxicity and has antioxidant and anti-cytotoxic effects in melanocytes.

Regarding the mechanism of the protective effects of Sanqi-CK on melanocytes, we found that GR activity and the GSH/GSSG ratio were reduced in $\mathrm{H}_{2} \mathrm{O}_{2}$-treated melanocytes; however, addition of Sanqi-CK $(1.25 \mu \mathrm{g} / \mathrm{mL})$ significantly reversed these $\mathrm{H}_{2} \mathrm{O}_{2}$-induced effects. GR is an enzyme that catalyzes the reduction of GSSG to GSH [23]. GSH is a critical molecule for resisting oxidative stress and maintaining the reducing environment of a cell [32]. Thus, GR is an important antioxidative enzyme and plays an integral role in maintaining the appropriate redox status in cells. Glutathione levels and reduced/oxidized glutathione balance status were previously reported to be abnormal in vitiligo [33] and rhododendrol-induced depigmentation [34]. Our results therefore suggest that Sanqi-CK can protect melanocytes against oxidative stress by enhancing glutathione reduction and modulating the redox status, which may be a good preventive or treatment strategy for vitiligo and rhododendrol-induced leukoderma.

Author Contributions: Conceptualization, L.Y., H.Z. and I.K.; methodology, L.Y.; software, L.Y.; validation, L.Y., S.X. and H.Z.; formal analysis, S.T., S.L., Y.K. and S.X.; investigation, S.T., S.L., Y.K. and S.X.; data curation, S.T., S.L.; writing-original draft preparation, S.T., L.Y.; writing-review and editing, L.Y.; visualization, S.T., Y.K. and S.L.; supervision, I.K.; project administration, L.Y., H.Z. All authors have read and agreed to the published version of the manuscript.

Funding: This research received no external funding. 
Institutional Review Board Statement: All procedures were conducted according to the Guiding Principles for the Care and Use of Laboratory Animals and were approved by the Committee for Animal Experiments at Osaka City University (Project code: 18042 and 2020/1/21 date of approval, Osaka, Japan).

Informed Consent Statement: Not applicable.

Data Availability Statement: The data presented in this study are available on request from the corresponding author.

Acknowledgments: We appreciate the cooperation and help of our secretary Kumiko Mitsuyama. Paraffin blocks were embedded, and sections were cut in the Research Support Platform of the Osaka City University Graduate School of Medicine.

Conflicts of Interest: The authors declare no conflict of interest.

\section{References}

1. Fitzpatrick, T.B.; Szabo, G. The melanocyte: Cytology and cytochemistry. J. Investig. Dermatol. 1959, 32, 197-209. [CrossRef]

2. Denat, L.; Kadekaro, A.L.; Marrot, L.; Leachman, S.A.; Abdel-Malek, Z.A. Melanocytes as instigators and victims of oxidative stress. J. Investig. Dermatol. 2014, 134, 1512-1518. [CrossRef] [PubMed]

3. Ezzedine, K.; Eleftheriadou, V.; Whitton, M.; van Geel, N. Vitiligo. Lancet 2015, 386, 74-84. [CrossRef]

4. Picardo, M.; Dell'Anna, M.L.; Ezzedine, K.; Hamzavi, I.; Harris, J.E.; Parsad, D.; Taieb, A. Vitiligo. Nat. Rev. Dis. Primers 2015, 1, 15011. [CrossRef] [PubMed]

5. Taieb, A. Intrinsic and extrinsic pathomechanisms in vitiligo. Pigment. Cell Res. 2000, 13 (Suppl. S8), 41-47. [CrossRef]

6. Maresca, V.; Roccella, M.; Roccella, F.; Camera, E.; Del Porto, G.; Passi, S.; Grammatico, P.; Picardo, M. Increased sensitivity to peroxidative agents as a possible pathogenic factor of melanocyte damage in vitiligo. J. Investig. Dermatol. 1997, 109, 310-313. [CrossRef]

7. Schallreuter, K.U.; Moore, J.; Wood, J.M.; Beazley, W.D.; Gaze, D.C.; Tobin, D.J.; Marshall, H.S.; Panske, A.; Panzig, E.; Hibberts, N.A. In vivo and in vitro evidence for hydrogen peroxide $\left(\mathrm{H}_{2} \mathrm{O}_{2}\right)$ accumulation in the epidermis of patients with vitiligo and its successful removal by a UVB-activated pseudocatalase. J. Investig. Dermatol. Symp. Proc. 1999, 4, 91-96. [CrossRef] [PubMed]

8. Jimbow, K.; Chen, H.; Park, J.S.; Thomas, P.D. Increased sensitivity of melanocytes to oxidative stress and abnormal expression of tyrosinase-related protein in vitiligo. Br. J. Dermatol. 2001, 144, 55-65. [CrossRef]

9. Abdel-Malek, Z.A.; Jordan, C.; Ho, T.; Upadhyay, P.R.; Fleischer, A.; Hamzavi, I. The enigma and challenges of vitiligo pathophysiology and treatment. Pigment. Cell Melanoma Res. 2020, 33, 778-787. [CrossRef]

10. Passi, S.; Grandinetti, M.; Maggio, F.; Stancato, A.; De Luca, C. Epidermal oxidative stress in vitiligo. Pigment. Cell Res. 1998, 11, 81-85. [CrossRef]

11. Peng, M.; Yi, Y.X.; Zhang, T.; Ding, Y.; Le, J. Stereoisomers of Saponins in Panax notoginseng (Sanqi): A Review. Front. Pharmacol. 2018, 9, 188. [CrossRef]

12. Duan, L.; Xiong, X.; Hu, J.; Liu, Y.; Li, J.; Wang, J. Panax notoginseng Saponins for Treating Coronary Artery Disease: A Functional and Mechanistic Overview. Front. Pharmacol. 2017, 8, 702. [CrossRef] [PubMed]

13. Du, Y.; Fu, M.; Wang, Y.T.; Dong, Z. Neuroprotective Effects of Ginsenoside Rf on Amyloid-beta-Induced Neurotoxicity in vitro and in vivo. J. Alzheimers Dis. 2018, 64, 309-322. [CrossRef]

14. Xie, W.; Meng, X.; Zhai, Y.; Zhou, P.; Ye, T.; Wang, Z.; Sun, G.; Sun, X. Panax Notoginseng Saponins: A Review of Its Mechanisms of Antidepressant or Anxiolytic Effects and Network Analysis on Phytochemistry and Pharmacology. Molecules 2018, 23, 940. [CrossRef]

15. Zhao, H.; Han, Z.; Li, G.; Zhang, S.; Luo, Y. Therapeutic Potential and Cellular Mechanisms of Panax Notoginseng on Prevention of Aging and Cell Senescence-Associated Diseases. Aging Dis. 2017, 8, 721-739. [CrossRef] [PubMed]

16. Bellei, B.; Pitisci, A.; Ottaviani, M.; Ludovici, M.; Cota, C.; Luzi, F.; Dell'Anna, M.L.; Picardo, M. Vitiligo: A possible model of degenerative diseases. PLoS ONE 2013, 8, e59782. [CrossRef] [PubMed]

17. Xiao, J.; Chen, H.; Kang, D.; Shao, Y.; Shen, B.; Li, X.; Yin, X.; Zhu, Z.; Li, H.; Rao, T.; et al. Qualitatively and quantitatively investigating the regulation of intestinal microbiota on the metabolism of panax notoginseng saponins. J. Ethnopharmacol. 2016, 194, 324-336. [CrossRef]

18. Xia, W.; Sun, C.; Zhao, Y.; Wu, L. Hypolipidemic and antioxidant activities of sanchi (radix notoginseng) in rats fed with a high fat diet. Phytomedicine 2011, 18, 516-520. [CrossRef]

19. Song, W.; Wei, L.; Du, Y.; Wang, Y.; Jiang, S. Protective effect of ginsenoside metabolite compound K against diabetic nephropathy by inhibiting NLRP3 inflammasome activation and NF-kappaB/p38 signaling pathway in high-fat diet/streptozotocin-induced diabetic mice. Int. Immunopharmacol. 2018, 63, 227-238. [CrossRef]

20. Yang, Q.; Lin, J.; Zhang, H.; Liu, Y.; Kan, M.; Xiu, Z.; Chen, X.; Lan, X.; Li, X.; Shi, X.; et al. Ginsenoside Compound K Regulates Amyloid beta via the Nrf2/Keap1 Signaling Pathway in Mice with Scopolamine Hydrobromide-Induced Memory Impairments. J. Mol. Neurosci. 2019, 67, 62-71. [CrossRef] 
21. Yang, F.; Yang, L.; Wataya-Kaneda, M.; Yoshimura, T.; Tanemura, A.; Katayama, I. Uncoupling of ER/Mitochondrial Oxidative Stress in mTORC1 Hyperactivation-Associated Skin Hypopigmentation. J. Investig. Dermatol. 2018, 138, 669-678. [CrossRef]

22. Kim, Y.J.; Kim, M.J.; Kweon, D.K.; Lim, S.T.; Lee, S.J. Quantification of Hypopigmentation Activity In Vitro. J. Vis. Exp. 2019, e58185. [CrossRef]

23. Meister, A. Glutathione metabolism and its selective modification. J. Biol. Chem. 1988, 263, 17205-17208. [CrossRef]

24. Ito, S.; Wakamatsu, K. Biochemical Mechanism of Rhododendrol-Induced Leukoderma. Int. J. Mol. Sci. 2018, 19, 552. [CrossRef]

25. Abe, Y.; Okamura, K.; Kawaguchi, M.; Hozumi, Y.; Aoki, H.; Kunisada, T.; Ito, S.; Wakamatsu, K.; Matsunaga, K.; Suzuki, T. Rhododenol-induced leukoderma in a mouse model mimicking Japanese skin. J. Dermatol. Sci. 2016, 81, 35-43. [CrossRef] [PubMed]

26. Abe, Y.; Hozumi, Y.; Okamura, K.; Kawaguchi, M.; Kunisada, T.; Aoki, H.; Suzuki, T. A Mouse Model of Leukoderma Induced by Rhododendrol. J. Dermatol. Sci. 2016, 84, e86. [CrossRef]

27. Kuroda, Y.; Takahashi, Y.; Sakaguchi, H.; Matsunaga, K.; Suzuki, T. Depigmentation of the skin induced by 4-(4-hydroxyphenyl)2-butanol is spontaneously re-pigmented in brown and black guinea pigs. J. Toxicol. Sci. 2014, 39, 615-623. [CrossRef]

28. Yang, L.; Yang, F.; Teng, L.; Katayama, I. 6-Shogaol Protects Human Melanocytes against Oxidative Stress through Activation of the Nrf2-Antioxidant Response Element Signaling Pathway. Int. J. Mol. Sci. 2020, 21, 3537. [CrossRef] [PubMed]

29. Wang, C.-Z.; McEntee, E.; Wicks, S.; Wu, J.-A.; Yuan, C.-S. Phytochemical and Analytical Studies of Panax Notoginseng (Burk.) F.H. Chen. J. Nat. Med. 2006, 60, 97-106. [CrossRef]

30. Xu, C.; Wang, W.; Wang, B.; Zhang, T.; Cui, X.; Pu, Y.; Li, N. Analytical methods and biological activities of Panax notoginseng saponins: Recent trends. J. Ethnopharmacol. 2019, 236, 443-465. [CrossRef] [PubMed]

31. Dai, C.; Liang, Y.; Hao, H.; Zheng, X.; Xie, L.; Guan, T.; Zhou, Y.; Wang, G. Global detection and identification of components from Yunnan Baiyao based on liquid chromatography hybrid ion trap time-of-flight mass spectrometry. J. Sep. Sci. 2013, 36, 1935-1944. [CrossRef] [PubMed]

32. Couto, N.; Wood, J.; Barber, J. The role of glutathione reductase and related enzymes on cellular redox homoeostasis network. Free Radic. Biol. Med. 2016, 95, 27-42. [CrossRef] [PubMed]

33. Zedan, H.; Abdel-Motaleb, A.A.; Kassem, N.M.; Hafeez, H.A.; Hussein, M.R. Low glutathione peroxidase activity levels in patients with vitiligo. J. Cutan. Med. Surg. 2015, 19, 144-148. [CrossRef] [PubMed]

34. Kondo, M.; Kawabata, K.; Sato, K.; Yamaguchi, S.; Hachiya, A.; Takahashi, Y.; Inoue, S. Glutathione Maintenance Is Crucial for Survival of Melanocytes after Exposure to Rhododendrol. Pigment. Cell Melanoma Res. 2016, 29, 541-549. [CrossRef] [PubMed] 